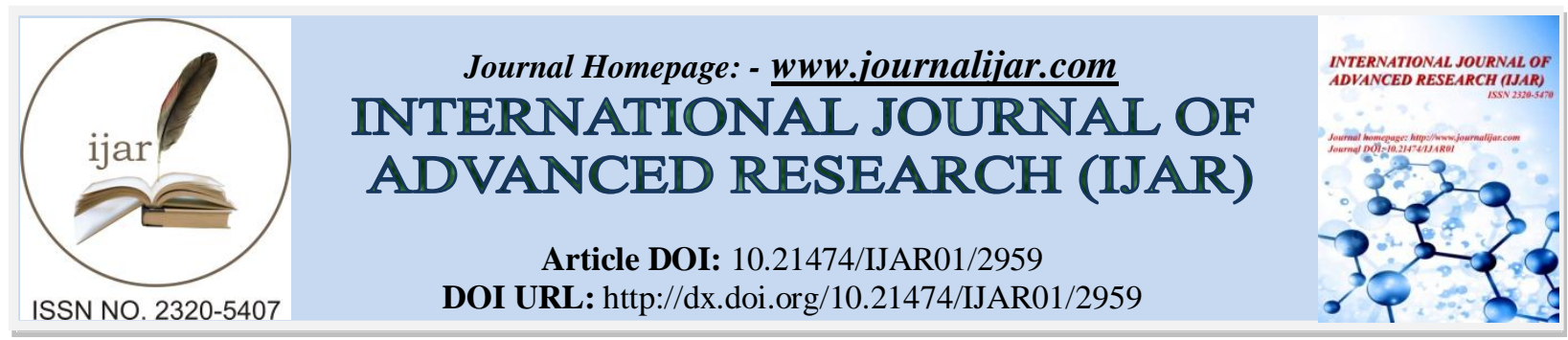

RESEARCH ARTICLE

\title{
A CRITICAL REVIEW ON PARAMETRIC INFLUENCE OF JOURNAL BEARING
}

Paramvir Yadav ${ }^{1}$, Kaushal Kumar ${ }^{2}$, Vinay Singh ${ }^{2}$ and Gurprit Singh ${ }^{3}$.

1. Assistant Professor, Department of mechanical engineering, S.G.T. University, Gurugram(Haryana).

2. Research Scholar, Department of mechanical engineering, G.J.U.S. \& T. Hisar (Haryana).

3. Research Scholar, Department of mechanical engineering, Thapar University, Patiala (Punjab).

\section{Manuscript Info}

Manuscript History

Received: 29 November 2016

Final Accepted: 26 December 2016

Published: January 2017

\section{Abstract}

The innovatory modifications in the field of journal bearing are at quite slow speed. In the field of tribology tools requires high stiffness to improve accuracy. Thus it is necessary for the designer to study the parametric influence of journal bearing quantitative as well as qualitative. This article provides a brief review for journal bearing from available literature in recent years. Since there have been lot of developments in design, the parametric optimization has been performed by many researchers. Numbers of researchers have been working on different aspects of performance of the journal bearing, ranging from temperature rise, geometry of grooves, damping, eccentricity ratio and clearance etc. Based on the state of art in bearing identification, valuable discussions are made with future directions.

Copy Right, IJAR, 2016,. All rights reserved.

\section{Introduction:-}

Now a days, hydrodynamic journal bearing are in high demand for their excellent properties such as long-term performance, negligible friction and almost zero wear particularly in Diesel engine, centrifugal compressors, pumps, motors, etc. Now a day, hydrodynamic journal bearing are in high demand for their excellent properties such as long-term performance, negligible friction and almost zero wear particularly in Diesel engine, centrifugal compressors, pumps, motors, etc. This type of bearing works on hydrodynamic principle, which involves with the rotation of shaft, creates an oil wedge that supports the shaft and relocates it within the bearing clearances. The shaft spinning within a journal bearing is actually separated from the journal bearing's metal facing by an extremely thin film of continuously supplied oil that prohibits metal to metal contact. In other words the hydrodynamic journal bearing works on hydrodynamic lubrication theory, which is concerned with separation of two surfaces in relative motion. 


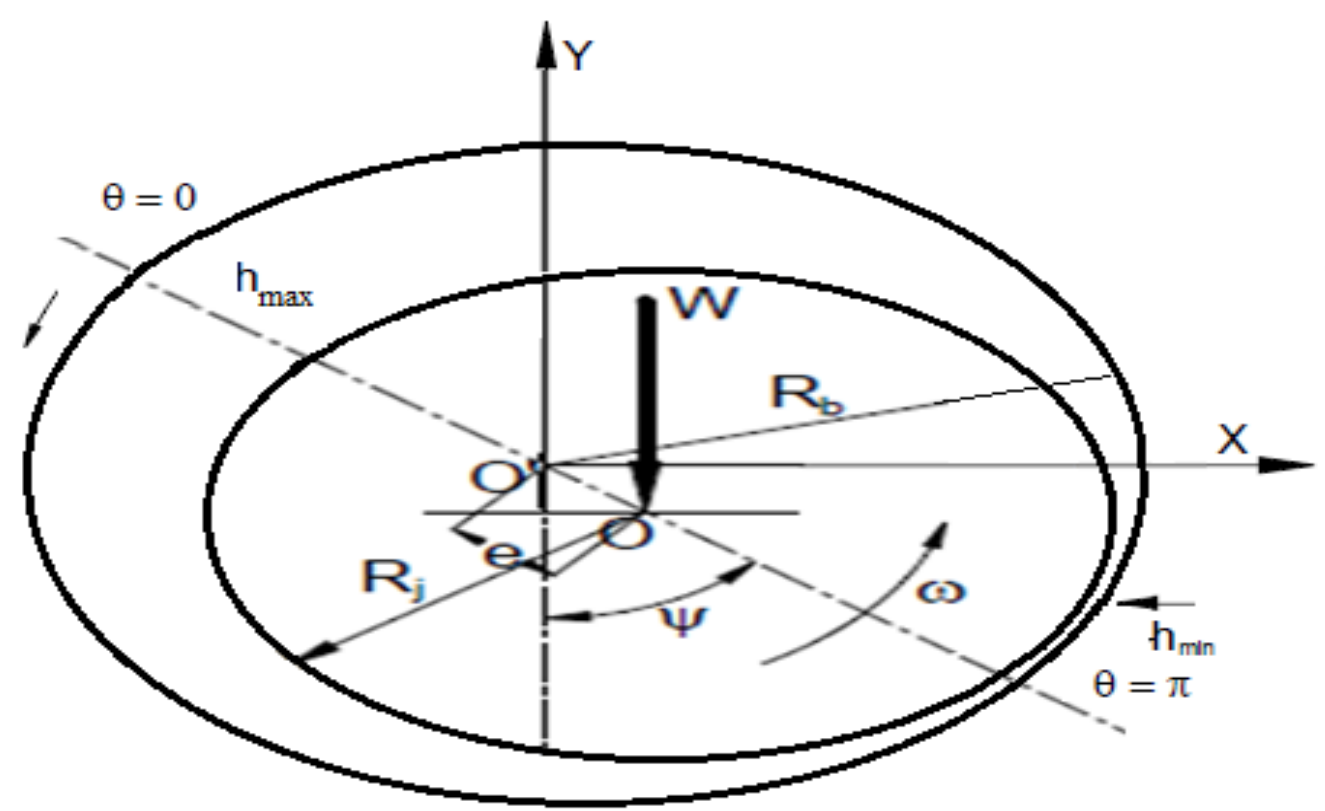

Figure 1:- Journal bearing geometry

Journal bearings shown in figure 1 have many designs to compensate for varying load requirements, machine speeds, cost, or dynamic properties. A stable bearing design holds the rotor at a fixed attitude angle during transient periods such as machine start-ups/shutdowns or load changes. The performance of a hydrodynamic journal bearing is governed by a number of bearing parameters, such' as radial clearance length, diameter, viscosity, groove geometry, location, etc. There are few assumption regarding hydrodynamic journal bearing are as the flow is laminar and isothermal with a constant vertical load W is applied on the journal. Geometry and co-ordinate system of the journal bearing is shown in fig 1 . The journal rotates with angular velocity $\omega$ and remains in equilibrium position under the action of external load, W. The journal centre $\mathrm{O}$ is eccentric to bearing centre $\mathrm{O}^{\prime}$. The film thickness $\mathrm{h}(\theta)$ varies from its maximum value $h_{\max }$ at bearing angle $\theta=0$ to its minimum value, $h_{\min }$ at $\theta=\pi$.

In this article, we present a review of hydrodynamic journal bearing from literature available in recent years. Since there have been lot of developments in design, the parametric optimization has been performed by many researchers. Numbers of researchers have been working on different aspects of performance of the journal bearing, ranging from temperature rise, geometry of grooves, damping, eccentricity ratio and clearance etc. Based on the state of art in bearing identification, valuable discussion is made and future directions are suggested.

\section{Literature Review:-}

First a remarkable work on Thermo-hydrodynamic study of journal bearing was done by Hughes and Osterle [1] and describes a relation between viscosity as a function of temperature and pressure of the lubricant inside the journal bearing for adiabatic conditions with examples Basri and Gethin [2] have investigated the thermal aspects of various noncircular journal bearing using adiabatic model. Cupillard et al. [3] have presented an analysis of lubricated conformal contact to study the effect of surface texture on bearing friction and load carrying capacity using computational fluid dynamics. The authors have reported that the coefficient of friction can be reduced if a texture of suitable geometry is introduced. Gertzos et al. [4] have investigated journal bearing performance with a NonNewtonian fluid i.e. Bingham fluid considering the thermal effect. Huiping Liu et al.[5] studied hydrodynamic journal bearings with elastic insert and found that the elastic deformation of the bearing had a significant influence on the rotor-bearing system, particularly for the polymeric-based materials. Jaw-Ren Lin et al. [6] numerically calculated oil film pressure by using Fourth Runge-Kutta method and this pressure is utilized to evaluate the load carrying capacity and the friction parameter. A comparison of the results between the Darcy model and Brinkman model is made to show the viscous shear effects provide an increase in the load capacity, as well as a decrease in the friction parameter. Nabhan et al.[7] solved Navier-Stokes equation with the aid of Simpson rule and calculated the pressures, drags and load carrying capacities by taking binary fluid mixture with different viscosity ratio. Hassan E. 
Rasheed [8] theoretically presented the effects of circumferential, axial and combined surface waviness on the performance of the hydrodynamic journal bearings by using Reynolds equation for Newtonian isoviscous lubricant. It was observed that when waviness number is approximately below nine, then circumferential waviness increases the load carrying capacity and decreases the friction variable. But the axial waviness is to always have an opposite effect on the load carrying capacity and friction variable. S.k.guha [9] analized the effect of isotropic roughness on the steady-state characteristics of hydrodynamic journal bearings terms of load capacity, attitude angle, end leakage flow rate, misalignment moment and friction coefficient are estimated for different values of roughness parameter, eccentricity ratio and degree of misalignment at unit slenderness ratio. Finite difference method is also used to measure steady-state oil film pressures by using Reynolds equation. Myung-Rae Cho et al.[10] presented the effects of circumferential groove on the minimum oil film thickness in engine bearings and used mobility method for journal locus analysis. It was observed that the circumferential $360^{\circ}$ groove only decreases the magnitude while $180^{\circ}$ half groove affects the shape and position of the minimum oil film thickness. NabarunBiswas and PrasunChakraborti[11] used physical properties of SAE-50 lubricant for analysis purpose in journal bearing. They involve with six time steps 10, 30, 50, 70, 90, and $110 \mathrm{sec}$ for unsteady analysis and found out that after $110 \mathrm{sec}$ the flow becomes steady. It was also observed that maximum pressure is observed at minimum oil film thickness with increasing value of roughness.

Sep et al.[12] analysed new design of the journal bearing with two-component surface layer and experimentally proved its usefulness in the case, where oil is contaminated by hard particles. In this new design the helical grooves are made on the bearing journal surface that should enable to eliminating contaminants from the frictional contact zone and concluded that if soft material is placed in the immediate vicinity of the grooves it will restrict the hard particles driving into the bearing surface which also decreases sensitivity. Byoung-Hoo Rho et al. [13] investigated acoustical properties of hydrodynamic journal bearing. The universal Reynolds equation is solved at each step of time using the finite difference method and the nonlinear transient motion of the journal centre is obtained by numerical integration of its acceleration using fourth order Runge-Kutta method. Byoung-Hoo Rho et al [14] investigated the effects of design parameters on the noise of rotor-bearing system supported by oil lubricated journal bearing. The Reynolds equation for finite width bearing under unsteady condition is applied for calculating pressure. It was observed that the radial clearance, mass eccentricity of the rotor and the width of the bearing considerably affect the A-weighted sound pressure level of the bearing. Wu et al.[15] studied wall slip problem by parametric quadratic programming method and generalized Reynolds equation with wall slip for two-dimensional flow is applied. It is observed that if limiting shear stress at bearing surface should be more than that at the journal surface, the wall slip avoided. Nikolakopoulo et al.[16] developed an analytical modal which shows the relationship among the friction force, wear depth and misalignment angles The Reynolds equation is used to calculate the friction force in equilibrium condition and found that friction function dependent on wear and misalignment of the bearing. Singh et al [17] theoretically performed steady-state thermodynamic analysis of an axial groove bearing by using Reynolds equation, energy equation and heat conduction equation with appropriate boundary conditions in the journal bearing. It was found that the fluid film temperature increases due to frictional heat resulting viscosity and load carrying capacity decreases. It was also observed that groove angle of $360^{\circ}$ and groove length (Half of the bearing length) promoted to decrease the maximum temperature and increase the load carrying capacity. Ron A.J. Van Ostayen [18] presented a mathematical optimization procedure to find the optimal film height distribution for a hydrodynamic bearing. Firstly this methodology is applied for a bearing with constant load and sliding speed. Then subsequently applied for a bearing with periodic load and sliding speed. Slider bearings with different shapes, loads and speeds are analyzed by new heuristic load optimization procedure along with Reynolds equation and found more efficient than general purpose optimization routine. Andras Z. Szeri [19] modified the structure of lubricant film by using double layer of lubricant into clearance space of bearing surfaces in place of single layer of lubricant. Basic Reynolds equation was used for composite films under the restrictive assumptions by applying boundary conditions. The low-viscosity lubricant reduced viscous dissipation, while the high-viscosity lubricants maintained the desirable thickness to separate out the bearing surfaces. It was also found that composite-film bearings have considerably lower frictional losses in comparison to other traditional bearings. Lui et al.[20] designed and fabricated a test rig to investigate the stability nature of the JRHB. It was found that the rolling bearing plays a protective role under IHP condition. K. M. Panday et al [21] analysis thin film lubricated journal bearing with different L/D ratios such as $0.25,0.5,1,1.5$, and 2 . It was observed that maximum pressure present at minimum oil film thickness. Also reported that shear stress is reduces on bearing and journal surface with increase in L/D ratio whereas turbulent viscosity of lubricant rises with increase in L/D ratio. NacerTala-Ighil et al [22] developed a numerical model based on finite difference method by using Reynolds equation to study the cylindrical textures shape effect on the performance of hydrodynamic journal bearing. Based on geometric arrangement of textures on the bearing surface, a comparison of 
considered twenty five cases is conducted. It was found that the minimum oil film thickness increased approximately by $1.8 \%$ and friction torque is decreased approximately by $1.0 \%$. Meybodi et al [23] developed a general methodology, to design the proper bearing in order to eliminate the deviation of final product in extrusion process. Three smooth curved dies with non-symmetric T-shaped sections at different off-centricities have been taken and for each die proper bearing has designed. It was found that the deviation of final product is eliminated to a great extent. McAllister and Rohde [24] optimized the load-carrying capacity of one-dimensional journal bearings for a given minimum film thickness by using a long bearing approximation, which is inaccurate in most practical design ranges. Hashimoto [25] presented an optimum study for high speed short journal bearings using successive quadratic programming. For Eccentricity $>0.8$ and L/D $>0.3$, the short bearing approximation predicts highly unreliable results. Peeyush vats et al [26] presented thermal analysis of journal bearing by using FEM analysis. Parameters like heat generated, temperature distribution and heat dissipation are studied. From results it is reported that difference between heat dissipated and heat generated in oil film was very large, which causes increase in temperature of the bearing and damaged the bearing pads.

Currently, due to advancement in computer technology, many researchers trying to use commercial computational fluid dynamics (CFD) programs in their investigations. The CFD code is differ from other relevant codes because full Navier-Stokes equations is used with provides a solution to complex flow problem, whereas finite difference codes are based on the Reynolds equation. Moreover, the CFD packages are applicable in very complex geometries. Authors used different computational codes to study the parametric influence of hydrodynamic journal bearing are listed below with their outcomes.

\begin{tabular}{|c|c|c|c|c|}
\hline Ref. & $\begin{array}{l}\text { Technique } \\
\text { used }\end{array}$ & Bearing type & Parameter & Analysis /Results \\
\hline [27] & CFD & $\begin{array}{l}\text { journal bearing with } \\
\text { smooth and } \\
\text { textured surface }\end{array}$ & $\begin{array}{l}\text { Surface texture on } \\
\text { eccentricity ratio } \\
\text { and frictional force }\end{array}$ & $\begin{array}{l}\text { Light loading condition increased minimum film } \\
\text { thickness and reduced frictional force and for } \\
\text { high loading conditions increasing pressure zone } \\
\text { decreases the frictional force. }\end{array}$ \\
\hline$[28]$ & CFD & $\begin{array}{l}\text { Central } \\
\text { circumferential } \\
\text { groove } \\
\text { hydrodynamic of } \\
\text { journal bearing }\end{array}$ & $\begin{array}{lr}\begin{array}{l}\text { Bearing } \\
\text { capacity, }\end{array} \\
\begin{array}{l}\text { cavitations } \\
\text { and }\end{array} \\
\text { fractione. }\end{array}$ & $\begin{array}{l}\text { Groove depth affect the load zone, bearing } \\
\text { carrying capacity, cavitations zone and vapour } \\
\text { fraction. }\end{array}$ \\
\hline$[29]$ & CFD & $\begin{array}{l}\text { Hydrodynamic } \\
\text { journal bearing }\end{array}$ & $\begin{array}{l}\text { L/D and } \\
\text { eccentricity ratios, } \\
\text { pressure }\end{array}$ & $\begin{array}{l}\text { FSI approach is used to find out pressure, stress } \\
\text { and deformation of hydrodynamic journal } \\
\text { bearing }\end{array}$ \\
\hline$[30]$ & CFD & $\begin{array}{l}\text { Journal bearing } \\
\text { with bingham fluid. }\end{array}$ & $\begin{array}{l}\text { Eccentricity ratio, } \\
\text { yield stress }\end{array}$ & $\begin{array}{l}\text { Fluent software compared with experimental and } \\
\text { theoretical results of Newtonian as well as } \\
\text { Bingham lubricants and found good agreement. } \\
\text { It is also concluded that the effect of yield stress } \\
\text { is small for low eccentricity ratio on the journal } \\
\text { bearing }\end{array}$ \\
\hline [31] & $\begin{array}{l}\text { CSD and } \\
\text { CFD }\end{array}$ & $\begin{array}{l}\text { Full } 360^{\circ} \text { journal } \\
\text { bearing. }\end{array}$ & $\begin{array}{l}\text { Deformation and } \\
\text { stress distribution }\end{array}$ & $\begin{array}{l}\text { The paper presented, these techniques is } \\
\text { effectively used for To finite element method } \\
\text { (FEM) was used to calculate stress distribution } \\
\text {.finding the surface deformation of bearing } \\
\text { under static load.effect of resulting forces is also } \\
\text { discussed. The simulation of elasto- } \\
\text { hydrodynamic lubrication have validated with } \\
\text { standard lubrication result }\end{array}$ \\
\hline$[32]$ & CFD-FSI & Journal bearing & $\begin{array}{l}\text { Deformation, } \\
\text { eccentricity ratios } \\
\text { and speeds }\end{array}$ & $\begin{array}{l}\text { Investigate interaction between elastic behavior } \\
\text { of bearing and fluid by developing models for } \\
\text { different eccentricity ratios and speeds. this } \\
\text { technique developed accurate performance of the } \\
\text { bearing }\end{array}$ \\
\hline [33] & CFD and & Thermo- & Pressure, & Finite volume and finite element method is used \\
\hline
\end{tabular}




\begin{tabular}{|c|c|c|c|c|}
\hline & FSI. & $\begin{array}{l}\text { hydrodynamic and } \\
\text { thermo- } \\
\text { elastohydrodynamic } \\
\text { analysis of full } \\
\text { journal bearing }\end{array}$ & $\begin{array}{l}\text { temperature and } \\
\text { velocity } \\
\text { distribution in the } \\
\text { fluid film, and } \\
\text { bearing surface } \\
\text { deformation }\end{array}$ & $\begin{array}{l}\text { to determine the characteristics under static load } \\
\text { condition. Distortion due to pressure is important } \\
\text { factor for determining the behavior of bearing. }\end{array}$ \\
\hline [34] & $\begin{array}{l}\text { COMSOL } \\
\text { models }\end{array}$ & $\begin{array}{l}\text { Hydrodynamic } \\
\text { bearing }\end{array}$ & $\begin{array}{l}\text { Pressure } \\
\text { distribution, } \\
\text { eccentricity ratio }\end{array}$ & $\begin{array}{l}\text { Pressure distribution is found out on infinite } \\
\text { (short as well as long) bearing under steady state } \\
\text { condition. It was predicted that increasing } \\
\text { pressure is proportional to eccentricity ratio and } \\
\text { pressure increases along the direction of } \\
\text { eccentricity }\end{array}$ \\
\hline [35] & $\begin{array}{l}\text { ANSYS. } \\
\text { MATLAB } \\
\text { software }\end{array}$ & $\begin{array}{l}\text { Bush type journal } \\
\text { bearing }\end{array}$ & Temperature & $\begin{array}{l}\text { It is showed that around } 12 \% \text { variations observe } \\
\text { between two methods. But Ansys gave more } \\
\text { exact solution than numerical method. }\end{array}$ \\
\hline [36] & CFD & Journal bearing & 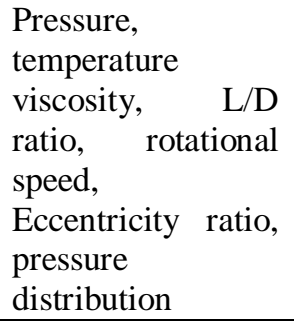 & $\begin{array}{l}\text { Software results validated with numerical results } \\
\text { got from Raimondi and Boyd chart method. It is } \\
\text { predicted that increasing temperature raises } \\
\text { pressure but decreases of attitude angle }\end{array}$ \\
\hline [37] & $\begin{array}{l}\text { CFD } \\
\text { (Gambit } \\
\text { and using } \\
\text { fluent } \\
6.3 .26 \text { ) }\end{array}$ & $\begin{array}{l}\text { Plain journal } \\
\text { bearing }\end{array}$ & $\begin{array}{l}\text { Pressure } \\
\text { distribution, } \\
\text { temperature and } \\
\text { viscosity }\end{array}$ & $\begin{array}{l}\text { It is observed that increasing frictional force } \\
\text { increases the temperature and reduces viscosity } \\
\text { as well as maximum pressure of lubricant }\end{array}$ \\
\hline$[38]$ & CFD & $\begin{array}{l}\text { Circular journal } \\
\text { bearing }\end{array}$ & $\begin{array}{l}\text { Pressure and } \\
\text { temperature } \\
\text { distribution }\end{array}$ & $\begin{array}{l}\text { When the viscosity is put constant, temperature } \\
\text { as well as pressure increases }\end{array}$ \\
\hline [39] & $\begin{array}{l}\text { CFD and } \\
\text { FSI }\end{array}$ & $\begin{array}{l}\text { Infinitely long } \\
\text { journal bearing }\end{array}$ & $\begin{array}{l}\text { Pressure and } \\
\text { temperature } \\
\text { variation }\end{array}$ & $\begin{array}{l}\text { It is found that maximum pressure occurred } \\
\text { nearer to the region of minimum film thickness }\end{array}$ \\
\hline [40] & CFD & Journal bearing & $\begin{array}{l}\text { Pressure } \\
\text { distribution, } \\
\text { friction force, } \\
\text { friction coefficient }\end{array}$ & $\begin{array}{l}\text { It is observed that dimple is useful for } \\
\text { lubrication performances and reduces friction } \\
\text { force but there is loss of load capacity. }\end{array}$ \\
\hline
\end{tabular}

\section{Common observations:-}

From the available literature it is clear that researchers have listed almost all aspects regarding performance characteristics of journal bearing, however there is a need to develop new mathematical models based on behaviour of rotor-bearing systems. Similarly more experimental work also needed to study the influencing parameters on performance of hydrodynamic journal bearings. CFD code set new level of precision in the research of journal bearing with accuracy. New experiments can be used available data more effectively, especially with the inherent practical constraints for measurements and development of new identification techniques. The load carrying capacity, fluid film thickness and eccentricity ratio of journal bearing are discussed briefly but the effect of time duration is also hidden in the available literature which may influence performance characteristics of journal bearing. 


\section{References:-}

1. W. Hughes and F. Osterle, "Temperature Effects in Journal Bearing Lubrication," ASLE Transactions, Vol. 1, no.1, pp 210-212, 1958

2. S. Basri and D.T. Gethin, "A Comparative Study of The Thermal Behaviour of Profile Bore Bearings," Tribology International, Vol. 23, pp 265-276, 1990

3. S. Cupillard, S. Glavatskih, M.J.Cervantes, "Computational Fluid Dynamics Analysis of A Journal Bearing with Surface Texturing," Proc. IMechE, Engineering Tribology, Vol. 222, no.2, pp 97-107, 2008

4. K.P. Gertzos, P.G. Nikolakopoulos, C.A. Papadopoulos, "CFD Analysis of Journal Bearing Hydrodynamic Lubrication by Bingham Lubricant," Tribology International, Vol. 41, no.12, pp 1190-1204, 2008

5. H. Liu, H. Xu , P. J. Ellison ,Z. Jin, “Application of Computational Fluid Dynamics And Fluid-Structure Interaction Method to The Lubrication Study of A Rotor-Bearing System," Tribology Letters, Vol. 38, pp 325336,2010

6. J. Lin, C. Hwang and R. Yang, "Hydrodynamic Lubrication of Long, Flexible, Porous Journal Bearings Using The Brinkman Model," Wear, Vol. 198, pp 156-164, 1996

7. M.B.W. Nabhan, G.A. Ibrahim and M.Z. Anabtawi, "Analysis of Hydrodynamic Journal Bearings Lubricated With A Binary Water-Based Lubricant,” Wear, Vol. 209, pp 13-20, 1997

8. H. E. Rasheed, "Effect of Surface Waviness on The Hydrodynamic Lubrication of A Plain Cylindrical Sliding Element Bearing," Wear, Vol. 223, pp 1-6, 1998

9. S.K. Guha, "Analysis of Steady-State Characteristics of Misaligned Hydrodynamic Journal Bearings with Isotropic Roughness Effects," Tribology International, Vol. 33, pp 1-12, 2000

10. M. Cho, H. Shin and D. Han, "A Study on The Circumferential Groove Effects on The Minimum Oil Film Thickness in Engine Bearings," KSME International Journal, Vol. 14, pp 737-743, 2000

11. N. Biswas and P. Chakraborti, "Transient Analysis Of 3 Lobe Bearing Considering Surface Roughness Effect For Gas Turbine," 6th BSME International Conference On Thermal Engineering (ICTE ), 2014

12. J. Sep, A. Kucaba-Pietal, "Experimental Testing of Journal Bearings With Two-Component Surface Layer in The Presence of An Oil Abrasive Contaminant," Wear, Vol. 249, pp 1090-1095, 2001

13. B. H. Rho, K.W. Kim, "Acoustical Properties of Hydrodynamic Journal Bearings," Tribology International, Vol. 36, pp 61-66, 2003

14. B. H. Rho, D.G. Kim and K.W. Kim, "Effects of Design Parameters on The Noise of Rotor-Bearing Systems," Tribology International, Vol.37, pp 599-605, 2004

15. C.W. Wu, G.J. Ma, "Abnormal Behaviour of A Hydrodynamic Lubrication Journal Bearing Cause by Wall Slip," Tribology International, Vol. 38, pp 492-499, 2005.

16. P. G. Nikolakopoulos, C. A. Papadopoulos, "A Study of Friction in Worm Misaligned Journal Bearings Under Severe Hydrodynamic Lubrication,” Tribology International, Vol.41, pp 461-472, 2008

17. U. Singh, L. Roy and M. Sahu, "Steady-State Thermo-Hydrodynamic Analysis of Cylindrical Fluid Film Journal Bearing with An Axial Groove," Tribology International, Vol. 41, pp 1135-1144, 2008

18. R.A.V.Ostayen, "Film Height Optimization of Dynamically Loaded Hydrodynamic Slider Bearings," Tribology International, Vol. 43, pp 1786-1793, 2010

19. A.Z. Szeri, "Composite-film Hydrodynamic Bearings," International Journal of Engineering Science, Vol. 48, pp 1622-1632, 2010

20. D. Lui, W. Zhao, B. Lu and J. Zhang, "A Zero Wear Assembly of A Hydrodynamic Bearing and A Rolling Bearing Assembly and Manufacturing," IEEE Conference, pp 1-4, 2011

21. K. M. Panday, P. L. Choudhury and N. P. Kumar, "Numerical Unsteady Analysis of Thin Film Lubricated Journal Bearing," International Journal of Engineering And Technology, Vol. 4, No. 2, 2012

22. N. Tala-Ighil, M. Fillon and P. Maspeyrot, "Effect of Textured Area on The Performances of A Hydrodynamic Journal Bearing," Tribology International, Vol. 44, pp 211-219, 2011

23. A. K. Meybodi, A. Assempourand and S. Farahani, "A General Methodology for Bearing Design in NonSymmetric T-Shaped Sections in Extrusion Process," Journal of Materials Processing Technology, Vol. 212, pp 249- 261, 2011

24. G.T. McAllister and S.M. Rohde, “Optimum Design of One-Dimensional Journal Bearings," J. Optimization Theory and Application, Vol.41, no. 4, pp 599-617, 1983

25. H. Hashimoto, "Optimization of Oil Flow Rate and Oil Film Temperature Rise in High Speed Hydrodynamic Journal Bearings,” Journal of Tribology Series, Vol. 34, pp 205-210, 1998

26. P. Vats, B.C. Sharma, S. Sharma, "Heat Transfer Through Journal Bearing: A Case Study," International Journal of Research in Engineering and Technology, Vol.3, no.10, pp 216-221, 2014 
27. Samuel Cupillard, Michel J. Cervantes And Sergei Glavatskih, "A CFD study of a Finite Textured Journal Bearing," 24th Symposium on Hydraulic Machinery and Systems, pp 1-11,2008

28. H. Jin, W. Zuo, "Simulation And Heat Transfer Calculation on A Journal Bearing with Center Circumferential Groove in Load Zone," International Journal of Advancements in Computing Technology, Vol. 5, no.1, 2013

29. S. C. Kumar, R. Ganapathi, "CFD Analysis on Hydrodynamic Plain Journal Bearing using Fluid Structure Interaction Technique," International Journal of Engineering Research \& Technology, Vol. 4, no.7, 2015

30. K.P. Gertzos, P.G. Nikolakopoulos, C.A. Papadopoulos, "Lubrication By Bingham Lubricant," Tribology International, Vol.41, pp 1190-1204, 2008

31. B. S. Shenoy, R. S. Pai, D. S. Rao, R. Pai, "Elasto-Hydrodynamic Lubrication Analysis Of Full $360^{\circ}$ Journal Bearing Using CFD And FSI Techniques," World Journal of Modelling and Simulation, Vol. 5, no. 4, pp. 315320, 2009

32. D. Dhande, D. W. Pande, V. Chatarkar, "Analysis Of Hydrodynamic Journal Bearing Using Fluid Structure Interaction Approach," International Journal of Engineering Trends and Technology, Vol.4, no.8, 2013

33. A. Ouadoud, A. Mouchtachi, N. Boutammacht, "Hydrodynamic Journal Bearing," Journal of Advanced Research in Mechanical Engineering, Vol. 2, no.1, pp. 33-38, 2011

34. R. M. Mane, S. Soni, "Analysis of Hydrodynamic Plain Journal Bearing," The Proceedings of COMSOL Conference in Bangalore, 2013

35. S. Torgal, R. Saini, "Calculation of Equivalent Oil Film Temperature of Journal Bearing Using ANSYS," International Journal of Science Technology \& Engineering, Vol. 1, no. 12, 2015

36. A. Panthi, J. Balwanshi, A. Chandravanshi, G. Gupta, " Design and Analysis of Hydrodynamic Journal Bearing Using Raimondi and Boyd Chart," International Journal of Core Engineering \& Management Vol. 2, no. 3, 2015

37. M. Sahu, A. K. Giri, A. Das, "Thermohydrodynamic Analysis Of A Journal Bearing Using CFD As A Tool," International Journal Of Scientific And Research Publications, Vol. 2, no. 9, pp 2250-3153, 2012

38. A. Singla, A. Kumar, S. Bala, P. Singh, A. Chauhan, "Thermo-Hydrodynamic Analysis On Temperature Profile Of Circular Journal Bearing Using Computational Fluid Dynamics," Proceedings of RAECS Chandigarh, 2014

39. P. Tiwari and V. Kumar, "Analysis Of Hydrodynamic Journal Bearing Using CFD And FSI Technique," International Journal Of Engineering Research \& Technology, pp 2278-0181 ,Vol. 3, no. 7, 2014

40. H. Yong, R. Balendra, "CFD Analysis on The Lubrication Behaviours Of Journal Bearing With Dimples," Proceedings of IEEE International Conference on Mechatronics And Automation, Changchun, China, 2009 